\title{
Assessment of preoperative exercise capacity in hepatocellular carcinoma patients with chronic liver injury undergoing hepatectomy
}

Masaki Kaibori ${ }^{1,5^{*}}$, Morihiko Ishizaki ${ }^{1}$, Kosuke Matsui ${ }^{1}$, Richi Nakatake ${ }^{1}$, Tatsuma Sakaguchi ${ }^{1}$, Daiki Habu ${ }^{2}$, Sawako Yoshiuchi ${ }^{3}$, Yutaka Kimura ${ }^{4}$ and A Hon Kon ${ }^{1}$

\begin{abstract}
Background: Cardiopulmonary exercise testing measures oxygen uptake at increasing levels of work and predicts cardiopulmonary performance under conditions of stress, such as after abdominal surgery. Dynamic assessment of preoperative exercise capacity may be a useful predictor of postoperative prognosis. This study examined the relationship between preoperative exercise capacity and event-free survival in hepatocellular carcinoma (HCC) patients with chronic liver injury who underwent hepatectomy.

Methods: Sixty-one HCC patients underwent preoperative cardiopulmonary exercise testing to determine their anaerobic threshold (AT). The AT was defined as the break point between carbon dioxide production and oxygen consumption per unit of time $\left(\mathrm{VO}_{2}\right)$. Postoperative events including recurrence of $\mathrm{HCC}$, death, liver failure, and complications of cirrhosis were recorded. Univariate and multivariate analyses were performed to evaluate associations between 35 clinical factors and outcomes, and identify independent prognostic indicators of event-free survival and maintenance of Child-Pugh class.

Results: Multivariate analyses identified preoperative branched-chain amino acid/tyrosine ratio (BTR) $<5$, alanine aminotransferase level $\geq 42 \mathrm{IU} / \mathrm{l}$, and $\mathrm{AT} \mathrm{VO} \mathrm{V}_{2}<11.5 \mathrm{ml} / \mathrm{min} / \mathrm{kg}$ as independent prognostic indicators of event-free survival. AT $\mathrm{VO}_{2}<11.5 \mathrm{ml} / \mathrm{min} / \mathrm{kg}$ and $\mathrm{BTR}<5$ were identified as independent prognostic indicators of maintenance of Child-Pugh class.
\end{abstract}

Conclusions: This study identified preoperative exercise capacity as an independent prognostic indicator of event-free survival and maintenance of Child-Pugh class in HCC patients with chronic liver injury undergoing hepatectomy.

Keywords: Liver cancer, Chronic liver injury, Hepatectomy, Exercise capacity, BCAA/tyrosine ratio

\section{Background}

Major surgery has been shown to increase oxygen demand by about $40 \%$, which may place severe stress on cardiopulmonary reserve [1]. Patients with high cardiopulmonary risk have traditionally been assessed using tests such as transthoracic echocardiography, dobutamine stress echocardiography, radionuclide ventriculography, and spirometry. However, these assessments have not been validated as preoperative screening tests, and provided mostly static

\footnotetext{
* Correspondence: kaibori@hirakata.kmu.ac.jp

${ }^{1}$ Department of Surgery, Hirakata Hospital, Kansai Medical University, 573-191 Hirakata, Osaka, Japan

${ }^{5}$ Masaki Kaibori, Department of Surgery, Hirakata Hospital, Kansai Medical University, 2-3-1 Shinmachi, 573-1191 Hirakata, Osaka, Japan

Full list of author information is available at the end of the article
}

measurements of cardiopulmonary performance [2-4]. Walking distance or ability to climb stairs have been used as subjective measurements of exercise tolerance, and have been shown to predict perioperative complications $[5,6]$. However, these measurements lack objectivity and do not detect silent cardiopulmonary abnormalities. Dynamic assessment of preoperative exercise capacity may be a useful predictor of short- and long-term postoperative prognosis. Cardiopulmonary exercise (CPX) testing measures oxygen uptake at increasing levels of work and predicts cardiopulmonary performance under conditions of stress, such as after surgery. In elderly patients undergoing major abdominal surgical procedures, the majority of deaths from cardiopulmonary complications 
occur in patients with an anaerobic threshold (AT) of $<11 \mathrm{ml} / \mathrm{min} / \mathrm{kg}[7,8]$.

Hepatocellular carcinoma $(\mathrm{HCC})$ is the fifth most common cancer worldwide [9]. Maintenance of good perioperative nutrition and metabolism may improve the prognosis of patients with HCC undergoing hepatectomy $[10,11]$. To date, few studies have examined the usefulness of preoperative CPX testing in patients undergoing hepatectomy. In the present study, we aimed to clarify whether preoperative exercise capacity was related to event-free survival in HCC patients with chronic liver injury undergoing hepatectomy.

\section{Methods}

\section{Patients}

HCC patients with chronic hepatitis or cirrhosis who were scheduled for liver resection at Hirakata Hospital of Kansai Medical University (Osaka, Japan) between December 2008 and April 2010 were screened for inclusion this study. A total of 66 HCC patients underwent curative resection (defined as macroscopic removal of all tumor). There was no in-patient mortality. Sixty-one of the 66 patients were analyzed in this study, and the other 5 were excluded because they were followed up at other hospitals. All patients gave written informed consent for participation in this study. The study protocol was approved by the institutional ethics committee.

\section{Cardiopulmonary exercise testing}

Patients underwent preoperative CPX testing using a bicycle ergometer with an incremental protocol (5.0, 7.5, and $10 \mathrm{~W} / \mathrm{min}$ ). Twelve-lead electrocardiography was used to monitor heart rate, ST segment deviation, and arrhythmias, at rest and continuously during the exercise and recovery periods. Blood pressure was recorded at rest and every 2 min during the exercise and recovery periods. Peak oxygen consumption per unit of time $\left(\mathrm{VO}_{2}\right)$ was obtained from breath-by-breath analysis of expired air. Peak $\mathrm{VO}_{2}$ was defined as the highest mean value during exercise when the subject could no longer continue pedaling at $60 \mathrm{rpm}$. The AT, indicating the onset of metabolic acidosis, was defined as the break point between carbon dioxide production and $\mathrm{VO}_{2}$ [12], or the point at which the ventilatory equivalent for oxygen and end-tidal oxygen partial pressure curves reached their respective nadirs before beginning to increase again [13]. Thus, AT was set at the time of maximum fat combustion [14]. The respiratory compensation point was set at the point at which the ventilatory equivalent for carbon dioxide was lowest before a systemic increase, and when the end-tidal carbon dioxide partial pressure reached a maximum and began to decrease [15]. Exercise was stopped when the patient requested it because of fatigue, pain, or headache, or if there was failure to maintain a speed greater than $40 \mathrm{rpm}$ for more than 30 seconds despite encouragement.

\section{Clinical variables and surgery}

Before surgery, each patient underwent conventional liver function testing and measurement of the indocyanine green retention rate at $15 \mathrm{~min}$ (ICGR15). Hepatitis virus infection screening was performed by testing for hepatitis $B$ surface antigen (HBsAg) and hepatitis $C$ virus antibody (HCVAb). Alpha-fetoprotein (AFP) and protein induced by vitamin $\mathrm{K}$ absence/antagonism-II (PIVKA-II) levels were measured in all patients. We used two methods to determine body composition: dual-energy X-ray absorptiometry (DEXA) [16] and bioelectrical impedance analysis (BIA) [17]. Total body mass, mineral-free lean mass (non-bone fat-free mass), fat mass, and truncal fat were measured by whole body DEXA. BIA was performed using the whole body 8-electrode approach with a 5-500 $\mathrm{kHz}$ multifrequency impedance analyzer (InBody720, BIOSPACE Co., Ltd, Tokyo, Japan). Intracellular body water (ICW), extracellular water (ECW), total body water (TBW), body cell mass, and ECW ratio (ECW/TBW) were measured.

Surgical procedures were classified according to the Brisbane terminology proposed by Strasberg et al. [18]. Anatomic resection was defined as resection of the tumor together with the related portal vein branches and corresponding hepatic territory, and was classified as hemihepatectomy (resection of half of the liver), extended hemihepatectomy (right trisectionectomy, or similar procedures on the left or for smaller resections), sectionectomy (resection of two Couinaud sub-segments [19]), or segmentectomy (resection of one Couinaud subsegment). All other procedures were classified as nonanatomical resection, which was frequently performed for peripheral or central tumors. Peripheral tumors and those with extrahepatic growth were treated by partial hepatectomy because this procedure achieved a sufficient surgical margin. Central tumors located near the hepatic hilum or major vessels were treated by enucleation only, because it was too difficult and/or dangerous to remove enough liver tissue to obtain adequate margins. One consultant pathologist reviewed all specimens for histologic confirmation of the diagnosis. The width of the surgical margin was measured as the distance from the tumor edge to the resection line.

\section{Follow-up}

Peri- and postoperative complications and deaths were recorded to determine morbidity and mortality following hepatectomy. Postoperative complications were defined and classified according to the modified Clavien system [20]. Briefly, Grade I was any deviation from the normal postoperative course that did not require special treatment, 
Grade II required pharmacological treatment, Grade III required surgical or radiological intervention without (IIIa) or with (IIIb) general anesthesia, Grade IV was any lifethreatening complication involving dysfunction of one (IVa) or multiple (IVb) major organs, and Grade V was death. Postoperative liver-related events recorded included recurrence of HCC, HCC-related death, postoperative liver failure, and complications of cirrhosis requiring hospitalization (hepatic encephalopathy, uncontrollable pleural effusion or ascites, and rupture of esophageal or gastric varices). The Child-Pugh class of every patient was determined preoperatively and every 6 months postoperatively.

All surviving patients were followed up at least every 3 months after discharge. Follow-up included physical examination, liver function testing, chest radiographs to check for pulmonary metastases, and ultrasonography, computed tomography, or magnetic resonance imaging to check for intrahepatic recurrence. Chest computed tomography was performed if the chest radiograph showed any abnormalities. Bone metastases were diagnosed by bone scintigraphy.

When recurrence of HCC was detected by changes in tumor markers or on imaging, recurrence limited to the remnant liver was treated by transarterial chemoembolization, lipiodolization, re-resection, or percutaneous local ablative therapy such as radiofrequency ablation. When extrahepatic metastases were detected, active treatment was undertaken in patients with good hepatic functional reserve (Child-Pugh class A or B) and good performance status (0 or 1$)$, while other patients were only given radiation therapy to relieve symptoms of bone metastases. Surgical resection was undertaken in patients with a solitary extrahepatic metastasis and no intrahepatic recurrence.

\section{Prognostic factors}

We performed univariate and multivariate analyses of 35 clinical factors to identify independent variables related to postoperative event-free survival and postoperative maintenance of Child-Pugh class. The patient factors investigated were gender, age, body mass index, alcohol abuse, HBsAg, HCVAb, non-hepatitis B or $\mathrm{C}$ virus infection, diabetes mellitus, white blood count, lymphocyte count, insulin, homeostasis model assessment of insulin resistance, and liver function (including albumin, total bilirubin, aspartate aminotransferase [AST], alanine aminotransferase [ALT], prothrombin time, cholinesterase, platelet count, alkaline phosphatase, ICGR15, total cholesterol, low density lipoprotein cholesterol, transferrin, transthyretin, retinolbinding protein $[\mathrm{RBP}]$, transthyretin $[\mathrm{TTR}]$, branched chain amino acid [BCAA]/tyrosine ratio [BTR], and Child-Pugh class). The tumor factors investigated were
AFP and PIVKA-II. The exercise parameters investigated were AT, $\mathrm{VO}_{2}$, and peak $\mathrm{VO}_{2}$. The body composition parameters investigated using DEXA were body mass, fat mass, fat-free mass, and whole-body mineral density. The body composition parameters investigated using BIA were ICW, ECW, TBW, protein, mineral, body fat mass, and body cell mass.

All the variables that were identified as significantly associated with event-free survival or maintenance of Child-Pugh class by univariate analyses were then examined using the Cox proportional hazards model to identify variables that were independently associated with event-free survival or maintenance of Child-Pugh class.

\section{Statistical analysis}

Continuous variables are presented as mean \pm standard deviation (SD). The significance of differences between groups was assessed using the chi-square test or MannWhitney $U$-test, as appropriate. The Kaplan-Meier method was used to calculate rates of event-free survival and maintenance of Child-Pugh class as of February 2012, and the significance of differences in survival rates was estimated using the generalized log-rank test. The Cox proportional hazards regression model (stepwise method) was used for multivariate analyses. In all analyses, $p<0.05$ was considered statistically significant.

\section{Results}

This study included 61 patients (45 male, 16 female; mean \pm SD age $=70 \pm 9$ years). Table 1 shows the perioperative characteristics of HCC patients. Postoperative complications were observed in five patients: Grade II complications in three patients (ascites and/or pleural effusion) and Grade IIIa complications in two patients (intra-abdominal abscess). We followed these 61 patients until February 2012, with a median follow-up time of 24 months (range 12-36 months). We analyzed the prognostic factors associated with event-free survival and maintenance of Child-Pugh class. Postoperative events were defined as death due to recurrence of HCC, recurrence of HCC, intractable pleural effusion or ascites, gastrointestinal bleeding, or hepatic encephalopathy. Of the 61 patients, seven died from recurrence of HCC, 22 developed recurrence of HCC, two developed intractable pleural effusion or ascites, two developed gastrointestinal bleeding, and two developed hepatic encephalopathy.

Child-Pugh class changed from class A preoperatively to class $\mathrm{B}$ postoperatively in nine patients, from class A to class $\mathrm{C}$ in one patient, and from class $\mathrm{B}$ to class $\mathrm{C}$ in one patient. 


\section{Table 1 Perioperative characteristics of HCC patients}

\begin{tabular}{|c|}
\hline Age (years) \\
\hline Gender (male/female) \\
\hline $\mathrm{HBV} / \mathrm{HCV} / \mathrm{NBC}$ \\
\hline Child-Pugh class (A/B) \\
\hline Diabetes mellitus (+/-) \\
\hline WBC count $(/ \mu \mathrm{l})$ \\
\hline Lymphocyte count $(/ \mu \mathrm{l})$ \\
\hline ICGR15 (\%) \\
\hline Albumin $(\mathrm{g} / \mathrm{dl})$ \\
\hline Total bilirubin (mg/dl) \\
\hline Cholinesterase (U/I) \\
\hline Triglyceride (mg/dl) \\
\hline Prothrombin time (\%) \\
\hline Platelet count $\left(\times 10^{4} / \mu \mathrm{l}\right)$ \\
\hline AST (U/l) \\
\hline $\mathrm{ALT}(\mathrm{U} / \mathrm{l})$ \\
\hline $\operatorname{RBP}(\mathrm{mg} / \mathrm{dl})$ \\
\hline TTR (mg/dl) \\
\hline BTR \\
\hline AFP $(n g / m l)$ \\
\hline PIVKA-II (mAU/ml) \\
\hline Esophageal and/or gastric varices $(+/-)$ \\
\hline Surgical procedure (limited/anatomic) \\
\hline Operation time (min) \\
\hline Operative blood loss (ml) \\
\hline Blood transfusion (+/-) \\
\hline Tumor size $(\mathrm{cm})$ \\
\hline Associated liver disease \\
\hline (normal/fibrosis or hepatitis/cirrhosis) \\
\hline
\end{tabular}

\section{$70 \pm 9$}

$45 / 16$

$12 / 32 / 15$

$56 / 5$

$8 / 53$

$5,000 \pm 1,319$

$1,484 \pm 580$

$16.1 \pm 7.8$

$3.8 \pm 0.4$

$0.81 \pm 0.21$

$232 \pm 64$

$85 \pm 43$

$92 \pm 12$

$15 \pm 8$

$43 \pm 27$

$42 \pm 28$

$3.3 \pm 1.4$

$16 \pm 6$

$5.09 \pm 1.46$

$994 \pm 5,028$

$1,283 \pm 2,209$

$15 / 46$

$35 / 26$

$329 \pm 130$

$1,011 \pm 1,351$

$9 / 52$

$4.42 \pm 4.09$

9/30/22

$5 / 56$

Data represent the mean \pm standard deviation or the number of patients. $H B V$ hepatitis $B$ virus, $H C V$ hepatitis $C$ virus, NBC non-hepatitis $B$ or $C$ virus, $W B C$ white blood cell, ICGR15 indocyanine green retention rate at $15 \mathrm{~min}$; $A L T$ alanine aminotransferase, $R B P$ retinol binding protein, $T R$ transthyretin, $B T R$ branched chain amino acid/tyrosine ratio, AFP a-fetoprotein, PIVKA-II protein induced by vitamin $\mathrm{K}$ absence/antagonism-II.

\section{Factors associated with event-free survival and} maintenance of child-pugh class

The preoperative factors significantly associated with event-free survival on univariate analyses were preoperative ALT, albumin, RBP, BTR, platelet count, AT $\mathrm{VO}_{2}$, peak $\mathrm{VO}_{2}, \mathrm{ICW}$, body cell mass, and total body protein (Table 2). The preoperative factors associated with maintenance of Child-Pugh class on univariate analyses were albumin, BTR, triglyceride, and AT $\mathrm{VO}_{2}$. Multivariate analyses (Cox proportional hazards model) of the factors associated with event-free survival on univariate analyses identified preoperative
Table 2 Results of univariate analyses of potential prognostic factors for event-free survival in HCC patients Variable No. of 1-year survival 3-year survival $\quad p$ value patients rate (\%) rate (\%)

Etiology

HBV $\quad 13 \quad 91.7$

HCV $\quad 33$

91.7

52.1

0.1144

NBC

78.1

29.0

AST (IU/I)

$\leq 43 \quad 30$

15

86.7

54.2

83.3

45.6

0.1961

$>43$

31

82.8

28.3

ALT (IU/I)

$\begin{array}{lll}\leq 42 & 30 \quad 93.1\end{array}$

53.3

0.01

$>42 \quad 31$

73.3

22.2

Albumin (g/dl)

$\geq 3.8 \quad 34$

87.9

51.0

0.0226

$<3.8 \quad 27$

76.9

11.5

$\mathrm{RBP}(\mathrm{mg} / \mathrm{dl})$

$\geq 3.3$

32

86.7

46.9

0.0210

$<3.3$

29

77.8

77.8

BTR

$\geq 5.0 \quad 33$

87.5

53.0

0.0238

$<5.0$

28

77.8

16.2

Platelet count $\left(10^{4} / \mu \mathrm{l}\right)$

$\geq 15 \quad 32$

85.7

52.1

0.0355

$<15 \quad 29$

80.6

20.9

AT VO $2(\mathrm{ml} / \mathrm{min} / \mathrm{kg})$

$\geq 11.5 \quad 32$

90.3

42.3

0.0266

$<11.5 \quad 29$

75.0

33.4

Peak $\mathrm{VO}_{2}(\mathrm{ml} / \mathrm{min} / \mathrm{kg})$

$\geq 16.5$

32

87.1

50.3

0.0331

$<16.5$

29

78.6

10.8

Intracellular body water (I/BW kg)

$\begin{array}{llll}\geq 0.33 & 32 & 90.3 & 35.8 \\ <0.33 & 29 & 75.0 & 30.3\end{array}$

Body cell mass ( $\mathrm{kg} / \mathrm{BW} \mathrm{kg})$

$\begin{array}{llll}\geq 0.47 & 32 & 90.3 & 34,0\end{array}$

$\begin{array}{llll}<0.47 & 29 & 75.0 & 33.3\end{array}$

Total body protein $(\mathrm{kg} / \mathrm{BW} \mathrm{kg})$

$\begin{array}{llll}\geq 0.14 & 35 & 85.3 & 36.3\end{array}$

$<0.14 \quad 26 \quad 78.3$

32.2

HBV hepatitis $B$ virus, $H C V$ hepatitis $C$ virus, $N B C$ non-hepatitis $B$ or $C$ virus, $A S T$ aspartate aminotransferase, $A L T$ alanine aminotransferase, $R B P$ retinol binding protein, $B T R$ branched chain amino acid/tyrosine ratio, $A T$ anaerobic threshold, $\mathrm{VO}_{2}$ oxygen consumption, $\mathrm{BW}$ body weight.

$\mathrm{BTR}<5, \mathrm{ALT} \geq 42 \mathrm{IU} / \mathrm{l}$, and $\mathrm{AT} \mathrm{VO}_{2}<11.5 \mathrm{ml} / \mathrm{min} / \mathrm{kg}$ as independent prognostic indicators of event-free survival (Table 3). Multivariate analyses (Cox proportional 
Table 3 Results of multivariate analyses of potential prognostic factors for event-free survival in patients with HCC

\begin{tabular}{|c|c|c|c|c|}
\hline Variable & Coefficient & SE & Relative risk & $p$ value \\
\hline BTR $(\geq 5$ vs. $<5)$ & 1.240 & 0.415 & 3.454 & 0.0028 \\
\hline ALT ( $\geq 42$ vs. $<42 \mathrm{IU} / \mathrm{I})$ & 1.045 & 0.418 & 2.841 & 0.0124 \\
\hline $\begin{array}{l}\text { AT VO }{ }_{2}(\geq 11.5 \mathrm{vs} \\
<11.5 \mathrm{ml} / \mathrm{min} / \mathrm{kg})\end{array}$ & 1.004 & 0.412 & 2.730 & 0.0148 \\
\hline
\end{tabular}

SE standard error, BTR branched chain amino acid/tyrosine ratio, $A L T$ alanine aminotransferase, $A T$ anaerobic threshold, $\mathrm{VO}_{2}$ oxygen consumption.

hazards model) of factors associated with maintenance of Child-Pugh class on univariate analyses identified preoperative AT $\mathrm{VO}_{2}<11.5 \mathrm{ml} / \mathrm{min} / \mathrm{kg}$ and $\mathrm{BTR}<5$ as independent prognostic indicators of maintenance of Child-Pugh class.

Figure 1 shows that there was a significant correlation between BTR and AT $\mathrm{VO}_{2}$ in $\mathrm{HCC}$ patients $(\mathrm{r}=0.410$, $\mathrm{Y}=8.139+0.583 * \mathrm{X}, p=0.0019)$.

\section{Outcomes}

There was a significant difference in the event-free survival rate between patients with preoperative $\mathrm{BTR} \geq 5.0$ and $<5.0(p=0.0238)$ (Figure 2A). There was also a significant difference in the rate of maintenance of ChildPugh class between patients with preoperative BTR $\geq 5.0$ and $<5.0(p=0.0494)$ (Figure 2B).

There was a significant difference in the eventfree survival rate between patients with $\mathrm{AT} \mathrm{VO}_{2}$ $\geq 11.5$ and $<11.5 \mathrm{ml} / \mathrm{min} / \mathrm{kg}(p=0.0266)$ (Figure 3A). There was also a significant difference in the rate of maintenance of Child-Pugh class between patients with $\mathrm{AT} \mathrm{VO}_{2} \geq 11.5$ and $<11.5 \mathrm{ml} / \mathrm{min} / \mathrm{kg}(p=0.0464)$ (Figure 3B).

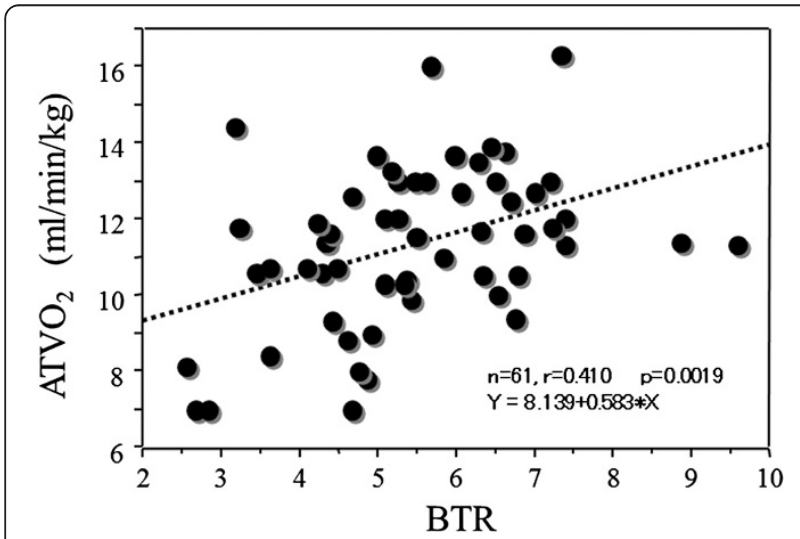

Figure 1 Relationships between preoperative BTR and AT $\mathrm{VO}_{2}$ in HCC patients. There was a significant correlation between BTR and $\mathrm{AT} \mathrm{VO}_{2}(r=0.410, Y=8.139+0.583 * \mathrm{X}, p=0.0019)$. BTR branched chain amino acid/tyrosine ratio, $A T \mathrm{VO}_{2}$ anaerobic threshold oxygen consumption.

\section{Discussion and conclusions}

We examined the relationships among preoperative CPX parameters, postoperative events including recurrence of $\mathrm{HCC}$, and change in Child-Pugh class in 61 patients undergoing hepatectomy. The variables derived from CPX testing included peak $\mathrm{VO}_{2}$, which is the maximum oxygen uptake at peak exercise. Previous studies indicated that peak $\mathrm{VO}_{2}$ was the most useful predictor of postoperative cardiopulmonary complications in patients undergoing radical esophagectomy with three-field lymphadenectomy [21] and patients undergoing surgical procedures for lung cancer [22-26]. The AT is defined as the point during exercise at which oxygen demand outstrips oxygen delivery and metabolism starts to become anaerobic. AT is a measure of the ability of the cardiopulmonary system to deliver adequate oxygen to tissues, and has the advantage of being independent of patient motivation. Reaching AT does not require high levels of physical stress and occurs well before peak $\mathrm{VO}_{2}$ [27]. The usefulness of measuring AT has been assessed predominantly in elderly patients undergoing major surgical procedures, allowing the development of an operative risk grading and treatment protocol $[7,8]$. An AT cut-off of $11 \mathrm{ml} / \mathrm{min} / \mathrm{kg}$, which is internationally recognized, is currently used to select patients for enhanced recovery programs after colorectal surgery. However, AT has not been found to be useful in the assessment of cardiopulmonary fitness of patients undergoing esophagectomy only [21].

This study identified $\mathrm{AT} \mathrm{VO}_{2}<11.5 \mathrm{ml} / \mathrm{min} / \mathrm{kg}$ as an independent prognostic indicator of both event-free survival and maintenance of Child-Pugh class, indicating that CPX testing can be used to prospectively evaluate the cardiopulmonary function of HCC patients with chronic liver injury undergoing hepatectomy. It is possible that CPX testing can be used to predict postoperative recurrence of $\mathrm{HCC}$ or liver dysfunction. It has recently been reported that hepatic impairment, particularly cirrhosis, leads to secondary insulin resistance and hyperinsulinemia, resulting in the promotion of carcinogenesis. Management of insulin resistance is therefore critical in patients with chronic liver disease, to protect liver function and prevent hepatocarcinogenesis. Alterations in glucose metabolism also affect fat metabolism (production of lipid peroxide and reactive oxygen species) $[28,29]$, which in turn may damage hepatocytes [30], leading to possible development of HCC [31]. It is difficult to manage insulin resistance associated with chronic liver disease, because restriction of caloric intake conflicts with the need to overcome malnutrition arising from hepatocellular damage. However, a reduction in body weight with exercise has been reported to be advantageous in obese patients with chronic liver disease [32]. The results of these studies and of our 


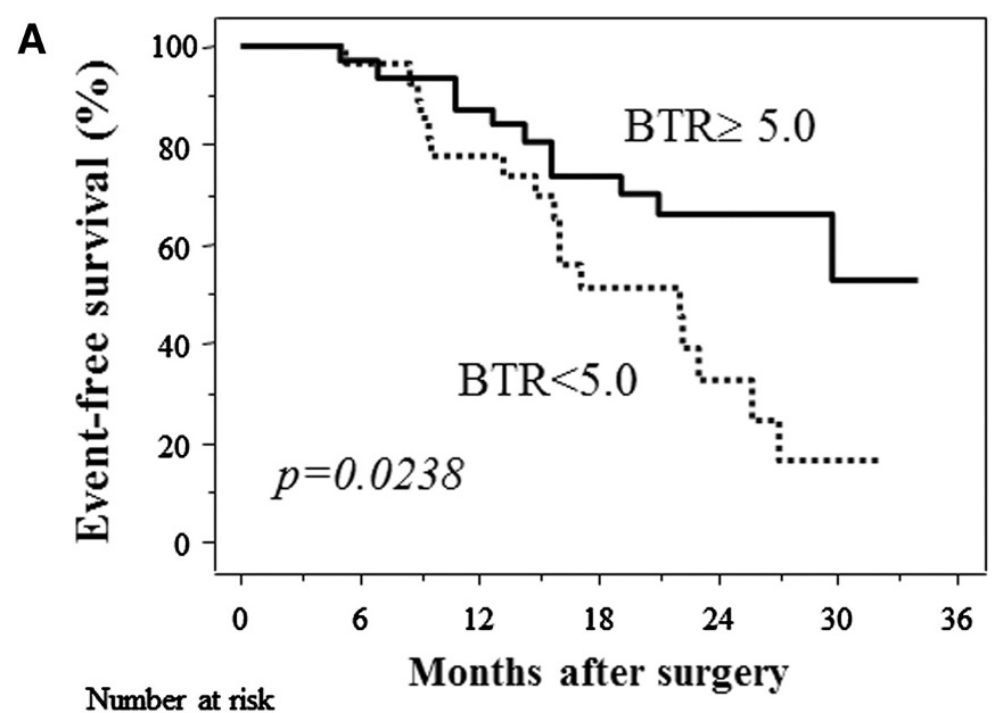

\section{$\mathrm{BTR} \geq 5.0$}

$\begin{array}{llllll}33 & 32 & 29 & 20 & 10 & 3\end{array}$

BTR $<5.0$

$\begin{array}{lllllll}\ldots \ldots . & 28 & 27 & 22 & 11 & 4 & 2\end{array}$

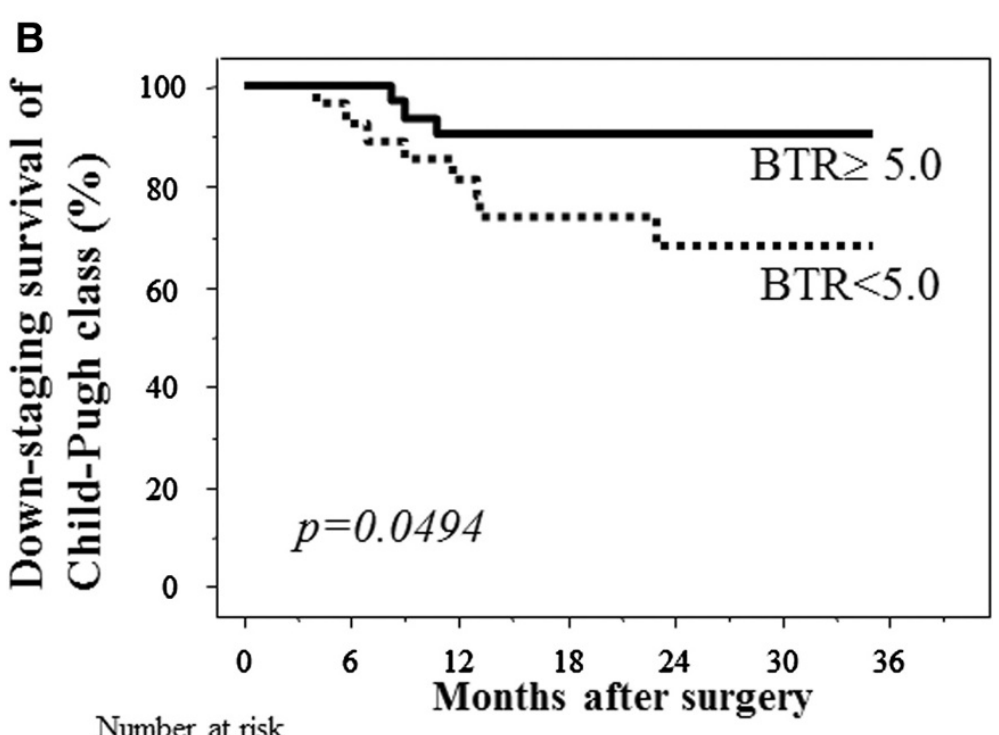

Number at risk

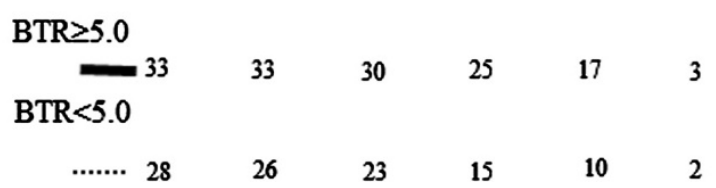

Figure 2 Comparisons of event-free survival and maintenance of Child-Pugh class after hepatectomy between patients with preoperative $\mathrm{BTR} \geq \mathbf{5 . 0}$ and $<\mathbf{5 . 0}$. (A) Event-free survival. The survival rate was significantly higher in patients with preoperative BTR $\geq 5.0$ (solid line) than BTR $<5.0$ (dotted line) $(p=0.0238)$. (B) Maintenance of Child-Pugh class. The rate of maintenance of Child-Pugh class was significantly higher in patients with preoperative BTR $\geq 5.0$ (solid line) than BTR $<5.0$ (dotted line) $(p=0.0494$ ). The numbers of patients at risk are shown below each graph. BTR branched chain amino acid/tyrosine ratio. 
A

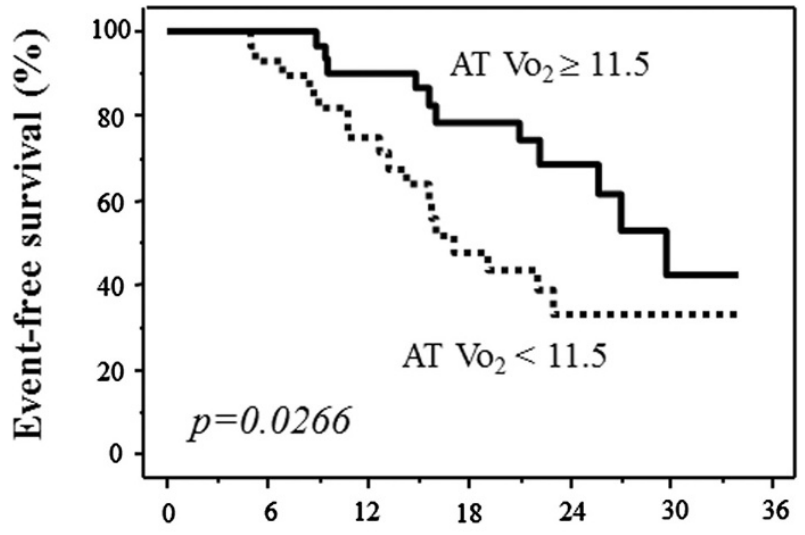

Number at risk

$\begin{array}{llllll}\text { AT Vo } 2 \geq 11.5 \mathrm{ml} / \mathrm{min} / \mathrm{kg}=32 & 32 & 29 & 19 & 10 & 3 \\ \text { AT } \mathrm{Vo} 2<11.5 \mathrm{ml} / \mathrm{min} / \mathrm{kg} \ldots \ldots . . .29 & 28 & 21 & 12 & 4 & 2\end{array}$

B

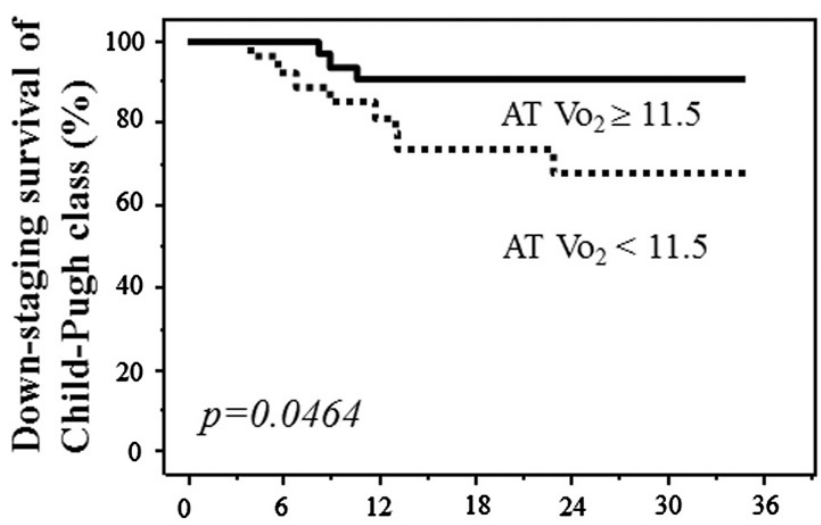

Number at risk

\section{Months after surgery}

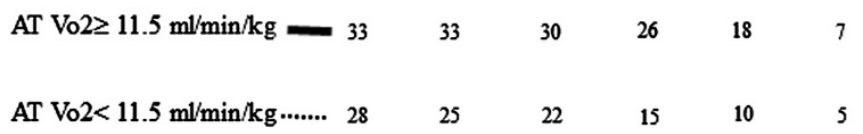

Figure 3 Comparisons of event-free survival and maintenance of Child-Pugh class after hepatectomy between patients with preoperative $A T \mathrm{VO}_{2} \geq 11.5 \mathrm{ml} / \mathrm{min} / \mathbf{k g}$ and $<11.5 \mathrm{ml} / \mathrm{min} / \mathbf{k g}$. (A) Event-free survival. The survival rate was significantly higher in patients with preoperative $A T V_{2} \geq 11.5 \mathrm{ml} / \mathrm{min} / \mathrm{kg}$ (solid line) than $\mathrm{AT} \mathrm{VO}_{2}<11.5 \mathrm{ml} / \mathrm{min} / \mathrm{kg}$ (dotted line) $(p=0.0266$ ). (B) Maintenance of Child-Pugh class. The rate of maintenance of Child-Pugh class was significantly higher in patients with preoperative $\mathrm{AT} \mathrm{VO}_{2} \geq 11.5 \mathrm{ml} / \mathrm{min} / \mathrm{kg}$ (solid line) than AT $\mathrm{VO}_{2}<11.5 \mathrm{ml} / \mathrm{min} / \mathrm{kg}$ (dotted line) $(p=0.0464)$. The numbers of patients at risk are shown below each graph. AT VO $\mathrm{O}_{2}$ anaerobic threshold oxygen consumption.

study indicate that hepatectomy for HCC patients with cirrhosis can be safely performed in patients with AT $\mathrm{VO}_{2} \geq 11.5 \mathrm{ml} / \mathrm{min} / \mathrm{kg}$.

When liver function is impaired, metabolism of amino acids is also impaired. Consumption of BCAAs in skeletal muscle is increased to compensate for the lack of energy production by the liver [33], and aromatic amino acids (AAAs) are abundant. The balance of BCAAs and AAAs is known as the Fischer ratio [34]. The tyrosine level alone can be used instead of the AAA level to determine BTR [33]. BTR decreases in patients with liver dysfunction, such as chronic hepatitis or cirrhosis [35-37]. BTR can therefore be used as a marker of liver function in patients with liver disease [33,35-37]. BTR also has a high degree of correlation with other markers of liver function [36,37]. In the present study, we found that BTR was an independent prognostic indicator of recurrence of $\mathrm{HCC}$ or progressive liver dysfunction. Prolonged BCAA supplementation can therefore improve the prognosis of $\mathrm{HCC}$ patients who have undergone 
hepatectomy. It is important to pay attention to the preoperative BTR when planning perioperative care. We found a significant correlation between BTR and AT $\mathrm{VO}_{2}$ in $\mathrm{HCC}$ patients.

In conclusion, preoperative exercise capacity and BTR were identified as independent prognostic indicators of event-free survival and maintenance of Child-Pugh class in $\mathrm{HCC}$ patients with chronic liver injury undergoing hepatectomy. These results suggest that pre- and postoperative intervention with exercise therapy and BCAA supplementation may be beneficial in patients with chronic liver injury.

\section{Competing interests}

The authors declare that they have no competing interests.

\section{Authors' contributions}

MK conducted the data analysis and drafted the manuscript. DH, YK and AHK conceived of the study, participated in its design, and helped draft the manuscript. MI, RN and TS participated in the study design and contributed to the data collection. KM participated in the study design and advised the analysis. SY contributed to study data collection. All authors contributed to the interpretation of the findings, and read and approved the final manuscript.

\section{Acknowledgements}

This work was supported in part by Grants-in-Aid from the Ministry of Health, Labor, and Welfare of Japan.

\section{Synopsis for table of contents}

In patients with hepatocellular carcinoma and hepatic dysfunction who underwent liver resection, preoperative exercise capacity and branchedchain amino acid/tyrosine ratio were identified as independent prognostic indicators of event-free survival and maintenance of Child-Pugh class. Improvement of preoperative exercise capacity may influence the short- and long-term postoperative prognosis in patients with chronic liver injury. Pre- and postoperative exercise therapy and branched-chain amino acid supplementation may be beneficial in these patients.

The study protocol was approved by the institutional ethics committee of Kansai Medical University (reference number: KMU H101036 and 080916).

\section{Author details}

${ }^{1}$ Department of Surgery, Hirakata Hospital, Kansai Medical University, 573-191 Hirakata, Osaka, Japan. ${ }^{2}$ Department of Nutritional Medicine, Graduate School of Human Life Science, Osaka City University, 545-8585 Osaka, Japan.

${ }^{3}$ Department of Nutrition Management, Hirakata Hospital, Kansai Medical University, 573-191 Hirakata, Osaka, Japan. ${ }^{4}$ Health Science Center, Hirakata Hospital, Kansai Medical University, 573-191 Hirakata, Osaka, Japan. ${ }^{5}$ Masaki Kaibori, Department of Surgery, Hirakata Hospital, Kansai Medical University, 2-3-1 Shinmachi, 573-1191 Hirakata, Osaka, Japan.

Received: 30 August 2012 Accepted: 19 July 2013

Published: 22 July 2013

\section{References}

1. Older $P, S$ mith $R$ : Experience with the preoperative invasive measurement of haemodynamic, respiratory and renal function in 100 elderly patients scheduled for major abdominal surgery. Anaesth Intensive Care 1988, 16:389-395.

2. Halm EA, Browner WS, Tubau JF, Tateo IM, Mangano DT, Study of Perioperative Ischemia Reserch Group: Echocardiography for assessing cardiac risk in patients having noncardiac surgery. Ann Intern Med 1996, 125:433-441.

3. Dunselman PH, Kuntze CE, Van Bruggen A, et al: Value of New York Herat Association classification, radionuclide ventriculography, and cardiopulmonary exercise tests for selection of patients for congestive heart failure studies. Am Heart J 1988, 116:1475-1482.
4. Mangano DT, London MJ, Tubau JF, Study of Perioperative Ischemia Reserch Group, et al: Dipyridamole thallium-201scintigraphy as a preoperative screening test: a reexamination of its predictive potential. Circulation 1991, 84:493-502.

5. Reilly DF, McNeely MJ, Doerner D, et al: Self-reported exercise tolerance and the risk of serious perioperative complications. Arch Intern Med 1999, 159:2185-2192.

6. Girish M, Trayner E Jr, Dammann O, Pinto-Plata V, Celli B: Symptom-limited stair climbing as a predictor of postoperative cardiopulmonary complications after high-risk surgery. Chest 2001, 120:1147-1151.

7. Older P, Hall A, Hader R: Cardiopulmonary exercise testing as a screening test for perioperative management of major surgery in the elderly. Chest 1999, 116:355-362

8. Older P, Smith R, Courtney P, Hone R: Preoperative evaluation of cardiac failure and ischemia in elderly patients by cardiopulmonary exercise testing. Chest 1993, 104:701-704.

9. Bosch X, Ribes J, Borras J: Epidemiology of primary liver cancer. Semin Liver Dis 1999, 19:271-285.

10. Ziegler TR: Perioperative nutritional support in patients undergoing hepatectomy for hepatocellular carcinoma. JPEN J Parenter Enteral Nutr 1996, 20:91-92.

11. Ishikawa Y, Yoshida H, Mamada Y, et al: Prospective randomized controlled study of short-term perioperative oral nutrition with branched chain amino acids in patients undergoing liver surgery. Hepatogastroenterology 2010, 57(99-100):583-590.

12. Beaver WL, Wasserman K, Whipp BJ: Bicarbonate buffering of lactic acid generated during exercise. J Appl Phsiol 1986, 60:472-478.

13. Whipp BJ, Wasserman K: Oxygen uptake kinetics for various intensities of constant-load work. J Appl Physiol 1972, 33:351-356.

14. Wasserman K, Hansen JE, Sue DY: Principles of exercise testing and interpretation. In Measurement of the physiological response to exercise. Edited by Wasserman K, Hansen JE, Sue DY, Whipp BJ. Philadelphia, PA: Lea and Febiger; 1987:27-46.

15. Snowden CP, Prentis JM, Anderson HL, et al: Submaximal cardiopulmonary exercise testing predicts complications and hospital length of stay in patients undergoing major elective surgery. Ann Surg 2010, 251:535-541.

16. Coin A, Sergi G, Minicuci N, et al: Fat-free mass and fat mass reference values by dual-energy X-ray absorptiometry (DEXA) in a 20-80 year-old Italian population. Clin Nutr 2008, 27:87-94.

17. Lehnert ME, Clarke DD, Gibbons JG, et al: Estimation ofbody water compartments in cirrhosis by multiplefrequency bioelectrical-impedance analysis. Nutrition 2001, 17:31-34.

18. Strasberg SM, Belghiti J, Clavien PA, et al: The Brisbane 2000 terminology of liver anatomy and resection: terminology committee of the International Hepato-Pancreato-Biliary Association. HPB 2000, 2:333-339.

19. Couinaud C (Ed): "Le Foie: Etudes Anatomiques et Chirurgicales". Paris: Masson; 1957.

20. Dindo D, Demartines N, Clavien PA: Classification of surgical complications: a new proposal with evaluation in a cohort of 6336 patients and results of a survey. Ann Surg 2004, 240:205-213.

21. Nagamatsu Y, Shima I, Yamana H, Fujita H, Shirouzu K, Ishitake T: Preoperative evaluation of cardiopulmonary reserve with the use of expired gas analysis during exercise testing in patients with squamous cell carcinoma of the thoracic esophagus. J Thorac Cardiovasc Surg 2001, 121:1064-1068.

22. Win $T$, Jackson $A$, Sharples $L$, et al: Cardiopulmonary exercise tests and lung cancer surgical outcome. Chest 2005, 127:1159-1165.

23. Nagamatsu Y, Terazaki Y, Muta F, Yamana H, Shirouzu K, Ishitake T: Expired gas analysis during exercise testing pre-pneumonectomy. Surg Today 2005, 35:1021-1025.

24. Smith TP, Kinasewitz GT, Tucker WY, Spillers WP, George RB: Exercise capacity as a predictor of post-thoracotomy morbidity. Am Rev Respir Dis 1984, 129:730-734.

25. Bechard D, Wetstein L: Assessment of exercise oxygen consumption as preoperative criterion for lung resection. Ann Thorac Surg 1987, 44:344-349.

26. Bolliger $C T$, Soler $M$, Stulz $P$, et al: Evaluation of high-risk lung resection candidates, pulmonary haemodynamics versus exercise testing: a series of five patients. Respiration 1994, 61:181-186.

27. Weisman IM: Cardiopulmonary exercise testing in the preoperative assessment for lung resection surgery. Semin Thorac Cardiovasc Surg 2001, 13:116-125. 
28. Avramoglu RK, Basciano H, Adeli K: Lipid and lipoprotein dysregulation in insulin resitant states. Clin Chim Acta 2006, 368:1-19.

29. Furukawa S, Fujita T, Shimabukuro M, et al: Increased oxidative stress in obesity and its impact on metabolic syndrome. J Clin Invest 2004, 114:1752-1761.

30. Valgimigli M, Valgimigli L, Trere D, et al: Oxidative stress EPR measurement in human liver by radical-probe technique: correlation with etiology, histology and cell proliferation. Free Radic Res 2002, 36:939-948.

31. Powell EE, Jonsson JR, Clouston AD: Steatosis: co-factor in other liver diseases. Hepatology 2005, 42:5-13.

32. Hickman IJ, Jonsson JR, Prins JB, et al: Modest weight loss and physical activity in overweight patients with chronoc liver disease results in sustained improvements in alanine aminotransferase, fasting insulin, and quality of life. Gut 2004, 53:413-419.

33. Moriwaki H, Miwa Y, Tajika M, Kato M, Fukushima H, Shiraki M: Branchedchain amino acids as a protein- and energy-source in liver cirrhosis. Biochem Biophys Res Commun 2004, 313:405-409.

34. Fisher JE, Rosen HM, Ebeid AM, James JH, Keane JM, Soeters PB: The effect of normalization of plasma amino acids on hepatic encephalopathy in man. Surgery 1976, 80:77-91.

35. Azuma Y, Maekawa M, Kuwabara Y, Nakajima T, Taniguchi K, Kanno T: Determination of branched-chain amino acids and tyrosine in serum of patients with various hepatic diseases, and its clinical usefulness. Clin Chem 1989, 35:1399-1403.

36. Shimizu H, Taniguchi K, Sugiyama M, Kanno T: Rapid enzymatic analysis of plasma for tyrosine. Clin Chem 1990, 36:32-35.

37. Mizuguchi T, Kawamoto M, Meguro M, Nakamura Y, Harada K, Kukita K, Hirata K: Prognostic impact of preoperative the branched-chain amino acid to the tyrosine ratio in hepatocellular carcinoma patients after initial hepatectomy. J Gastrointest Surg 2011, 15:1433-1439.

doi:10.1186/1471-230X-13-119

Cite this article as: Kaibori et al: Assessment of preoperative exercise capacity in hepatocellular carcinoma patients with chronic liver injury undergoing hepatectomy. BMC Gastroenterology 2013 13:119.

\section{Submit your next manuscript to BioMed Central and take full advantage of:}

- Convenient online submission

- Thorough peer review

- No space constraints or color figure charges

- Immediate publication on acceptance

- Inclusion in PubMed, CAS, Scopus and Google Scholar

- Research which is freely available for redistribution 